Jesús Muñoz: None declared, Luis Del Río: None declared, Marta Arévalo: None declared, Menna Rusiñol: None declared, Noemí Navarro: None declared, Víctor Parejo: None declared, Jordi Gratacos-Masmitja Grant/research support from: a grant from Pfizzer to study implementation of multidisciplinary units to manage PSA in SPAIN, Consultant of: Pfizzer, MSD, ABBVIE, Janssen, Amgen, BMS Novartis, Lilly, Speakers bureau: Pfizzer, MSD, ABBVIE, Janssen, Amgen, BMS, Novartis, Lilly

DOI: 10.1136/annrheumdis-2020-eular.2644

\section{SAT0469 PROSPECTIVE STUDY ASSESSING BONE MINERAL DENSITY AND RISK FACTORS FOR OSTEOPOROSIS IN PATIENTS WITH ANDROGEN DEPRIVATION THERAPY. PRELIMINARY CROSS-SECTIONAL RESULTS}

L. Gifre ${ }^{1}$, F. Elias ${ }^{2}$, P. Servian², R. Freixa ${ }^{2}$, O. Buisan Rueda $2 .{ }^{1}$ Hospital $^{2}$ Universitari Germans Trias i Pujol, Rheumatology, Badalona, Spain; ${ }^{2}$ Hospital Universitari Germans Trias i Pujol, Urology, Badalona, Spain

Background: Few studies have analysed the incidence and risk factors for osteoporosis (OP) development in patients with prostate cancer (PC) and androgen deprivation therapy (ADT)

Objectives: To assess risk factors for OP, bone turnover markers (BTM) and bone mineral density (BMD) in a cohort of patients with ADT, as well as the duration of ADT and previous treatments received for PC.

Methods: Ongoing prospective study including patients with ADT for PC. Risk factors for OP, BTM (total ALP, bone ALP, CTx), spinal X-Ray and BMD (Lunar, DPX) were assessed yearly since inclusion in the study (April 2018). Patients with known OP or previous antiosteoporotic treatment were excluded. The study was approved by the ethics committee, and all patients gave their signed consent. Herein we present the preliminary cross-sectional study at inclusion.

Results: Of the 83 patients attended at the Rheumatology Department during the study period, 75 were included with a mean age $75 \pm 5$ years and median ADT duration of 1 year. 18 were receiving concomitant radiotherapy and 7 docetaxel. When assessing risk factors for OP: $28 \%$ had previous fragility fractures and $24 \%$ had current alcohol intake. After X-Ray assessment, 14\% had morphometric vertebral fractures. Mean $25 \mathrm{OHD}$ at inclusion was $19 \pm 9 \mathrm{ng} / \mathrm{ml}(73 \%$ had $25 \mathrm{OHD}$ $<30 \mathrm{ng} / \mathrm{ml}$ ) and mean testosterone was $82 \pm 162 \mathrm{ng} / \mathrm{dL}(75 \%$ had levels $<50 \mathrm{ng} / \mathrm{dl})$. All patients had increased values of CTx and $9 \%$ had increased bone ALP levels. BMD showed up to $28 \%$ with densitometric OP and osteopenia in $56 \%$. Patients with OP were older ( $83 \pm 7$ vs $74 \pm 8$ years, $p=0.021$ ), had lower testosterone levels (16 vs $89 \mathrm{ng} / \mathrm{dl}, \mathrm{p}=0.004$ ), as expected lower BMD (at spine, proximal femur and even distal radius) and had more previous fragility fracture (75 vs $19 \%, p=0.022$ ) But it should be noted that $16 \%$ had high bone mass (HBM) mostly affecting spine BMD (in 6 patients combined with femoral osteopenia). All patients with HBM had high bone metastatic disease, and no differences were observed between patients with/without HBM when comparing BTM or calcium-phosphate metabolism.

Conclusion: Low bone mass (including osteoporosis and osteopenia) is frequent in patients with ADT as well as previous fragility fractures. Up to $16 \%$ had high bone mass, being mostly in patients with high volume metastatic disease Thus, all patients with ADT should undergo a bone health assessment and start antiosteoporotic treatment if required.

Disclosure of Interests: None declared

DOI: 10.1136/annrheumdis-2020-eular.5204

\section{SAT0470 $\quad$ FRAX AND DXA-BASED APPROACHES IN DIAGNOSTICS OF OSTEOPOROSIS RISK IN POSTMENOPAUSAL WOMEN WITH RHEUMATOID ARTHRITIS}

N. Grygorieva ${ }^{1}$, V. Povoroznyuk ${ }^{1}$, N. Dzerovych', M. Bystrytska ${ }^{1} .{ }^{1}$ State Institution «D. F. Chebotarev Institute of Gerontology NAMS of Ukraine", Department of Clinical Physiology and Pathology of Locomotor Apparatus, Kyiv, Ukraine

Background: Nowadays, the bone mineral density (BMD) measured by DXA and FRAX ${ }^{\circledR}$ are the most important methods for fracture risk assessment. Rheumatoid arthritis is a crucial disease for bone loss and osteoporosis development [1] which is included into FRAX algorithm. Ukrainian version of FRAX [2] is a new one and its value should also be assessed in patients with RA

Objectives: Our study was aimed to assess the parameters of BMD and FRAX in postmenopausal women with RA.

Methods: We have examined 635 postmenopausal females aged 50-89 years old which were divided into 2 groups: $1^{\text {st }}$ (control, $\left.n=313\right)$ - without any factors which have influence on bone metabolism, $2^{d}(n=322)$ - patients with RA. The 10-year probabilities of hip fracture and major osteoporotic fractures were calculated without BMD parameter using the Ukrainian FRAX model [2]. The DXA was used to measure the lumbar spine, femoral neck and total body BMDs; the T-score was calculated (DISCOVERY Wi, Hologic, Inc., USA).

Results: FRAX indexes for major osteoporotic and hip fractures were significantly higher in patients with RA (Me [25-75Q]): 9.7 [6.8-15.0] and 3.1 [1.5-6.2] \% compared to 6.0 [3.8-8.5] and $1.2[0.6-2.4] \%$ in females from the control group $(p<0.001) .45 .3 \%$ of women with RA required antiosteoporotic treatment according to Ukrainian FRAX threshold ratio without measure of BMD compared to $12.1 \%$ of subjects from control group. Only $3.4 \%$ of patients with RA had FRAX indexes which were less than low threshold (requirement of additional DEXA measurement) compared to $31.3 \%$ of females from control group

BMD of femoral neck and distal radius were reliably lower in subjects with RA and consisted $0.65 \pm 0.13$ and $0.69 \pm 0.12 \mathrm{~g} / \mathrm{cm}$ in $1^{\text {st }}$ and $2^{\mathrm{d}}$ groups, accordingly $(p<0.001)$ and $0.56 \pm 0.10$ and $0.58 \pm 0.09 \mathrm{~g} / \mathrm{cm}(\mathrm{p}=0.02)$ without any significant differences at lumbar spine and total body BMDs. $16.6 \%$ of subjects from the control group and $31.6 \%$ of females with RA had osteoporosis according to DXA parameters (T-score $\leq-2.5 \mathrm{SD}$ )

Conclusion: FRAX should be used more widely in clinical practice for detection of risk of osteoporotic fractures in subjects with RA

References:

[1] Povoroznyuk V.V., Grygorieva N.V., Karasevska T.A., Dzerovich N.I. Bone Mineral Density and Trabecular Bone Score Indices in Women with Rheu matoid Arthritis According to the Age and Use of Glucocorticoids. SM Rheumatol. 2017; 1(1): 1002

[2] Povoroznyuk V, Grygorieva N, Kanis JA, Johansson H, McCloskey EV. Ukrainian FRAX: criteria for diagnostics and treatment of osteoporosis // Pain. Joint. Spine.-2019.-9(4).-7-16.

Disclosure of Interests: None declared

DOI: 10.1136/annrheumdis-2020-eular.6028

\section{SAT0471 \\ EFFECTS OF ONE YEAR TOFACITINIB THERAPY ON BONE DENSITY AND BIOMARKERS OF BONE TURNOVER IN RHEUMATOID ARTHRITIS}

A. Hamar $^{1}$, A. Pusztai ${ }^{1}$, E. Végh ${ }^{1}$, Á. Horváth ${ }^{1}$, S. Szamosi ${ }^{1}$, Z. Pethö ${ }^{1}$, S. Szántó ${ }^{1}$, G. Szücs ${ }^{1}$, H. P. Bhattoa ${ }^{2}$, G. Tajti ${ }^{3}$, G. Panyi ${ }^{3}$, K. Hodosi ${ }^{1}$, Z. Szekanecz4. ${ }^{1}$ University of Debrecen, Rheumatology, Debrecen, Hungary; ${ }^{2}$ Universitiy of Debrecen, Department of Laboratory Medicine, Debrecen, Hungary; ${ }^{3}$ University of Debrecen, Biophysics and Cell Biology, Debrecen, Hungary; ${ }^{1}$ University of Debrecen, Rheumatology, Debrecen, Hungary

Background: Oral JAK inhibitor, tofacitinib appeared as a new therapeutic option, beside biological therapies, which has already proven its safety and effectivity in RA, but we lack of knowledge how it affects density of bone structures and bone turnover markers.

Objectives: The aim of this study was to assess the effects of one-year tofacitinib therapy on bone metabolism in patients with RA.

Methods: Altogether 30 RA patients with active disease were recruited and treated with tofacitinib in this 12-months follow-up study. Mean age of patients were $52.8 \pm 10.0$ years, duration of rheumatoid arthritis were $7.7 \pm 5.0$ years. Half of the patients haven't received biological treatment prior tofacitinib therapy, othe half of the patients switched to tofacitinib therapy after completing washout. 15 patients received $2 \times 5 \mathrm{mg}$ and 15 patients received $2 \times 10 \mathrm{mg}$ tofacitinib daily for 12 months. On both arms 2-2 patients have discontinued treatment and excluded from the study. Assessments were performed at baseline, month 6 and 12. Levels of $\mathrm{CRP}$ and IgM rheumatoid factor (RF) antibodies were measured by quantitaive nephelometry and levels of anti-CCP, sclerostin, osteocalcin (OC), P1NP were assesed by ELISA. Bone density was assesed by DXA (dual-energy X-ray absorptiometry, Lunar) and pQCT imaging techniques. Levels of DKK-1, OPG RANKL were measured by multiplex microbead immunoassay (BioLegend LEGENDplex). In addition, disease activity (DAS28), age and disease duration were also measured. Correlations were determined by Spearman's analysis. Univariate and multiple regression analysis using the stepwise method was applied to investigate independent associations between DXA measurements (dependent variables) and laboratory parameters (independent variables)

Results: Tofacitinib significantly reduced DAS28 $(p<0.001)$ and HAQ values $(p=0.001)$, also level of CRP $(p<0.001)$ and We $(p=0.014)$. With respect to bone biomarkers we have experienced significant increase in levels of $O C(p=0.013)$, OPG $(p=0.006)$, sclerostin $(p=0.026)$ and vitamin- $D(p=0.017)$ at month 6 , also in levels of OPG and vitamin-D $(p=0.004, p=0.003)$ at month 12 . We have found decrease in levels of CTX at month $6(p=0.009)$ and $12(p=0.003)$. When we examined the groups separately, we've found significant increase in levels of P1NP ( $p=0.027, p=0.005)$, OPG $(p=0.005, p=0.002)$ and vitamin-D $(p=0.001$ $\mathrm{p}=0.004)$ at month 6 and 12 , also in OC at month $6(\mathrm{p}=0.027)$ in Group A (2x5mg) In Group B (2x10mg) we've experienced a significant decrease in levels of phosphate and CTX at month 6 and $12(p=0.012, p=0.021$, and $p=0.005, p=0.007)$. 